\title{
Marine Spatial Planning in Romania: State of the art and evidence from stakeholders
}

Natașa VĂIDIANU ${ }^{1,2, *}$, Mădălina RISTEA²

${ }^{1}$ Faculty of Natural Sciences and Agricultural Sciences, Ovidius University of Constanta, 124 Mamaia Blv, Constanta, Romania

${ }^{2}$ Interdisciplinary Center for Advanced Research on Territorial Dynamics, University of Bucharest, 4-12

Regina Elisabeta Blv, Bucharest, Romania

*Corresponding author: natasa.vaidianu@geo.unibuc.ro, madalina_ristea@yahoo.com

\begin{abstract}
During the last decades, increasing demands on marine resources and unsustainable activities taking place in the marine area compromise the future use of the marine environment. In July 2014, the European Parliament and Council established a Guideline Framework for marine/maritime spatial planning (MSP). MSP is a useful and cost-effective tool for sustainable development, together with regulation and protection of the marine environment. Within this context, Romania has started to proceed and incorporate it in the national legislation framework; in 2017, it has also established a competent authority for its implementation so that marine spatial plans can be enacted by 31 March 2021. In this study, a first approach for MSP framework in Romania was developed, enabling the mapping of all current human activities related to shipping, oil and gas exploitation, fisheries, tourism and environmental status, in order to identify overlaps or potential conflicts among users. This paper identifies key challenges and concerns anticipated to emerge from incorporation of MSP in the national spatial planning framework as it is currently organized: a) Romanian stakeholders have a relatively poor understanding of European, national and regional sea planning regulations, b) concerns related to MSP implementation at regulatory level, c) huge need for sharing of MSP-relevant information for a coherent planning, d) challenges of assessing the needs of interconnected ecosystems (including relevant EU and international legislation). In this context, our study covers highly actual aspects concerning the way the marine spatial planning process evolves and will contribute to deliver a coherent approach to reduce conflicts of the Romanian marine environment, a proper MSP implementation, as well as minimizing the pressures and impacts on the marine resources.
\end{abstract}

Keywords: marine resources and sectors; spatial plans; public participation; regulations; Black Sea

\section{Highlights:}

Review of Romania's legal regime on MSP.

MSP implementation issues are discussed.

It has not shown a tendency to engage public in marine spatial plans design.

43\% of invited stakeholders did not hear about MSP directive. 
Lack of coherence with legal instruments could be challenging for future of MSP.

\section{Introduction}

Demands for marine resources has been increased worldwide and the need for sustainable development and marine conservation have been addressed (UNDP, 2030 Agenda for Sustainable Development). From the oldest times, humans utilized goods and services that have been derived directly or indirectly from the marine environment and they have exploited marine resources without the implementation of adequate management strategies that aimed to ensure the sustainability of these systems (Frau, 2010). Black Sea environment was marked by lack of management strategies which has led to the decline of marine resources and to high levels of pollution because of invasive species introduction, unregulated public access of goods and benefits provided by the sea, as well as natural conditions induced by semi-enclosed specificity (Avoyan et al., 2017). During the time, a strong need to implement efficient management policies that prevent environmental problems, improve the excessive degradation of Black Sea marine resources and their services was highly raised by decisions makers and international associations like Black Sea Commission, Black Sea Economic Commission or Black Sea Coast Guard cooperation forum.

The use of Europe's seas is increasing and gives rise to potential conflicts and competition for maritime space, both between different users and between maritime uses and the preservation of the marine environment (Appiott et al., 2014; Tuya et al., 2014; Jay and Toonen, 2015). This development increases the demand for Marine Spatial Planning (MSP), an instrument that is essential for resource efficiency in maritime activities (Jones et al., 2016). MSP is a tool used to resolve these conflicts and ensure sustainable use of the marine environment (Ahler and Douvere, 2007; Gee et al., 2017). MSP provides a framework for the management of human sea uses in a context of intensifying economic activity in sea basins around Europe (Ritchie, 2014; Becker-Weinberg, 2015; Stanchev et al., 2017; Rodrigues, 2017; Tsilimigkas and Rempis, 2017; Smith and Jentoft, 2017). MSP supports sustainable use of marine resources in line with the EU Sustainable Development Strategy and the requirement of the Marine Strategy Framework Directive (MSFD) on the application of the ecosystem approach by providing the means to effectively control human use of the marine space (EU Commission Communication, 2008; Abramic et al., 2015).

The legal provisions required EU Member States to engage in the preparation of marine spatial plans according to the Directive 2014/ 89/EU and to transpose it into national laws until 18 September 2016. MSP framework and implementation steps were designed by institutions like IOC-UNESCO, UNEP or FAO, within many initiatives, studies and reports (Ehler, 2014). Many countries already designated marine spatial areas, but conflicts can arise where management plans have been developed on a sector-by-sector basis, without sufficient consideration of the effects on other users or the environment (Edwards and Evans, 2017). The MSP process is acquiring the same legal status as terrestrial spatial planning and should be related with the integrated management of coastal zones (ICZM), an earlier initiative implemented after EU Recommendation in 2002 (Gissi and Suarez de Vivero, 2016). Also, for the implementation of MSP, all 
dimensions of maritime space should be taken into consideration because of the multi-uses in the same place and time (Pınarbaşı et al., 2017; Tsilimigkas and Rempis, 2017).

According to Ehler and Douvere (2007, 2009), one of the most important principles for a successful MSP implementation demands strong reliable geo-spatial datasets in order to establish operational marine spatial plans. Moreover, for the implementation of MSP to be accepted by the society, it is essential that there will be transparency and active involvement of local communities at all levels of planning (Flannery et al., 2018). Engagement with stakeholders from the start and throughout the process was identified as an essential element of any successful participatory undertaking (Reed, 2008; Gopnik et al., 2012). If stakeholders do not believe there is a problem or see how planning may improve the situation, they will be less likely to participate (Calado et al., 2012). More specifically, research suggests that, in order for MSP to achieve acceptance and success, stakeholders must be included in every stage of the process (Pomeroy and Douvere, 2008).

The European Commission (EC) intention is to support the development of MSP processes. To accomplish this initiative, EC started several studies on various aspects of MSP since 2008 (DG MARE website): a study on the legal aspects of MSP (2008); a study on the economic effects of MSP (2010), which concluded that economic effects of MSP are reduced transaction costs for new maritime activities and an improved investment climate and a study considering the potential of MSP in the Mediterranean (2011). Based on these preparatory actions, the Commission proposed legislative action on MSP in 2013. The EU has already cofinanced several projects on MSP in the Baltic Sea, in the North Sea, in the Atlantic, in the Celtic Seas, in the Adriatic Sea (European MSP platform website, Pınarbaşı et al., 2017). Currently, EC is co-financing a project on MSP in the Black Sea, between Romania and Bulgaria, but this transboundary initiative is seen as an initial step assuming the transposition of directive in national legislation and setting an institutional structure, respectively a national committee.

Given the above statements, the present paper focuses on the enabling and constraining conditions to implement marine spatial planning in Romania by learning from the ideas of different maritime stakeholders through performing an ex ante evaluation. The paper starts with background characteristics and methodological specifications, followed by aspects related to major economic sectors and presents the current MSP implementation status, as collected from stakeholder responses. The paper ends with a discussion on the future of MSP in Romania, given the sensitive environment and geopolitics in the Black Sea.

\section{Background of the study area}

\subsection{Study area characteristics}

The Romanian EEZ has a surface of $22.486 \mathrm{~km}^{2}$ and the territorial sea about $4084 \mathrm{~km}^{2}$. The Romanian marine water borders were disputed during the time as follows: between Romania and Ukraine was commonly established after International Court of Justice in 2009, and no EEZ and territorial water border with Bulgaria so far. There is currently no MSP around Romanian Exclusive Economic Zone (EEZ), apart from some temporary fishing closure areas and several natural reserves (Fig. 1). The Romanian Black Sea coastline concentrates natural and anthropogenic features significant at national and international level and represents 
$5.3 \%$ of the total Black Sea coastline. In Romania's coastal regions live around 900000 people (4.5\% of the total population), responsible for approx. EUR 5.5 billion of gross value added and for roughly 5\% (470000 people) of total national employment. From genetically, evolutionary, morphological, ecological, socioeconomic and coastal management points of view, it comprises two sectors: i) the northern part (the Danube Delta Biosphere Reserve), 162km long between Musura Bay (north of Sulina town) and Cape Midia, with great ecological value and ii) the southern part (the economic South), between Cape Midia and Vama Veche, associated with big hotels, refineries, ports and related infrastructure, under increasing economic and tourism development.

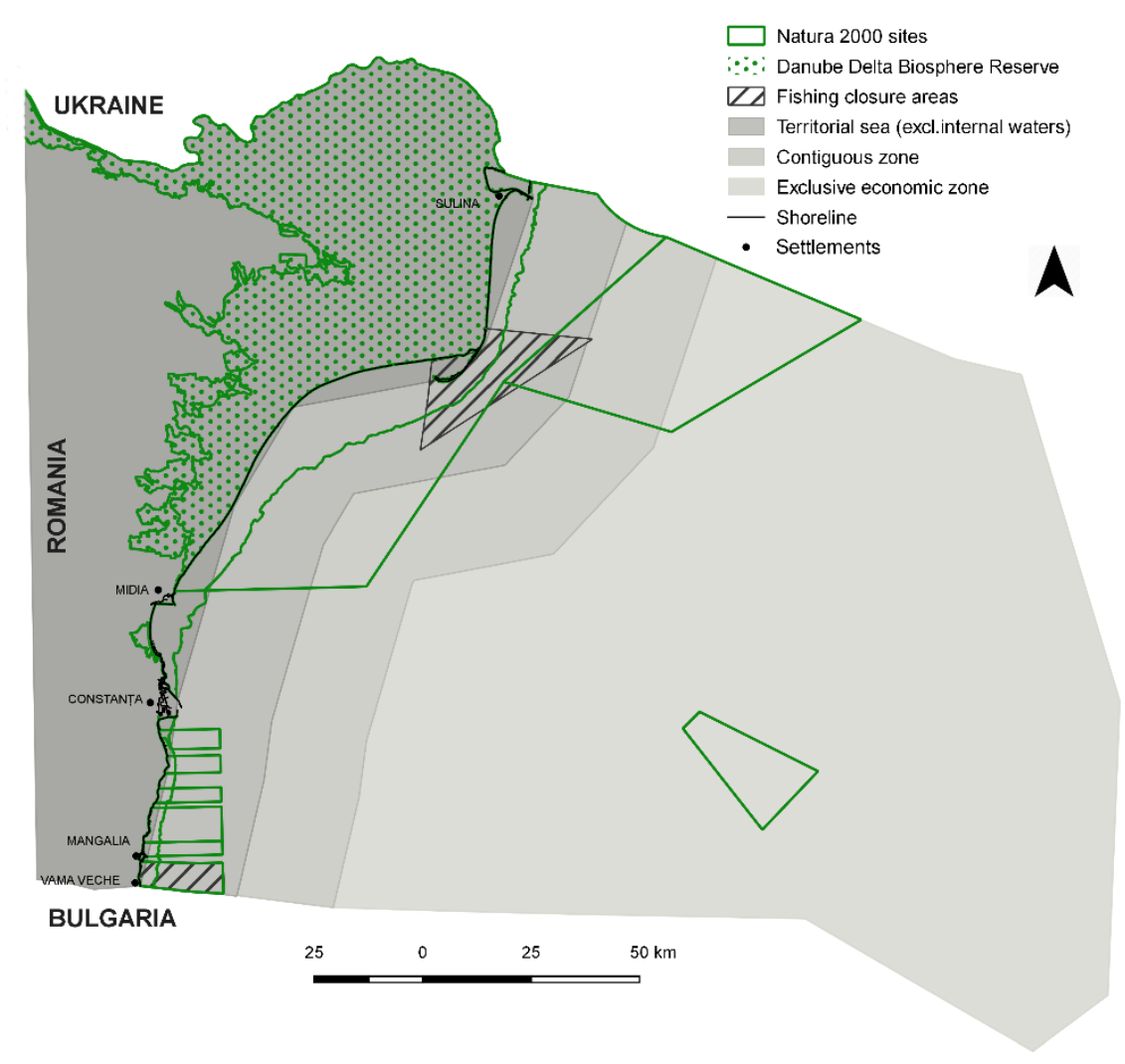

Fig. 1. Study area map, representing natural reserves, Natura 2000 sites and fishing closure areas. Danube Delta Biosphere Reserve has a special status of protection, extending offshore until 40 meters depth. RO SPA Black Sea covers the entire coast, with the exception of Constanta Port

2.2. Anthropogenic pressures on the Romanian Black Sea environment and key sectors for Blue Growth Romanian coast is very competitive among economic activities such as shipbuilding and ship repair, shipping and transport, coastal and maritime tourism, fisheries or offshore oil and gas. Therefore, regulations related to coastal and marine areas are both a national and regional concern and an important role from the Blue Growth perspective (European Commission, 2008; Blue Growth, 2012). A maritime cluster is emerging and links firms and business associations in the maritime sector, educational and research institutions and national authorities (http://clustero.eu/romanian-maritime-cluster/Maritime Cluster website). A short description of major economic sectors with strong impact and pressure on marine environment will be provided below. 
Shipbuilding and repair has a long tradition and high-quality infrastructure is in place for both maritime and fluvial ships, yearly generating EUR 530 million and 35.250 jobs. $98 \%$ of the ships built in Romania are exported. The main activity in this area is the manufacture of commercial transport vessels. Despite competition from Asia, the Romanian shipbuilding industry is improving its competitiveness by investing in green technologies and innovation to capitalise on the need for cheaper and cleaner transport from the Black Sea to Central Europe. It benefits from an excellent higher education system, experience in research, a favourable geographical position and connectivity between the Danube River and the Black Sea (DG MARE Report, 2014).

Maritime transport has also an important role, with a value of EUR 187 million and 8780 jobs. The share of maritime transport in the maritime economy has declined in the recent years while the share of coastal tourism has increased, followed by oil and gas and then shipbuilding and repair. Constanta port is the biggest port in the Black Sea and has been the core of maritime activities for decades. There is also an inland waterway transport route from Constanta, directly to Central European countries on Danube River.

Coastal tourism is one of the most important and promising economic activities in Romania in terms of value (EUR 402 million) and employment (47730 jobs), primarily due to the coastal area potential with a wide range of natural and cultural resources, including ecosystem-based tourism in the Danube Delta (Văidianu, 2013a). But this activity is based on seasonal characteristics. The summer season lasts from 1 June until 31 August, when the population exponentially increases and the coast is exploited as a recreational resource both for visitors and residents. According to the Government's strategic vision, the sector should focus on diversifying and restoring the influx of foreign tourists, which is closely linked with the further development of touristic services and transport infrastructure.

Offshore oil and gas reserves in the Black Sea, as well as the associated offshore and Midia port infrastructures, are strong assets to the development potential of this sector, including the Caspian-Black Sea energy corridor. Offshore oil is the fastest-growing sector, with a value of EUR 88 million and 3781 persons employed and it is supported by extraction technologies, research and equipment available in Romania and EU, and by a shipbuilding sector capable of producing tankers and offshore platforms. Recently, new stocks (mainly gas) were discovered in the Romanian waters of the Black Sea.

Fisheries sector is not expected to grow much further. Romanian fisheries entered into a crisis due to the new political and economic context, but also due to the ecological changes in the marine system such as eutrophication, pollution, invasive species or overfishing. Today, mainly artisanal/subsistence sector for local fishers, very small artisanal boats and angling techniques are present, with a value of EUR 88 million and 6440 persons employed. The main ports used by fishermen for landing catches are Mangalia, Olimp, Costinesti, Mamaia, Cape Midia and Sulina. However, Romania has no specialized fishing ports on the Black Sea. In 2012, the number of fishing enterprises in the Romanian fleet totalled 91, with the vast majority (79\%) owning a single vessel. Only $18 \%$ of enterprises owned between two and five fishing vessels (European Maritime and Fisheries Fund website). 


\subsection{Romanian experience, jurisdiction and legislation applied in MSP process}

Until 2015, only land planning was officially made by Romanian authorities and approved by Minister of Regional Development and Public Administration. Each town or commune have local plans. There are four municipality plans under review: Urban Zoning Plan for coastal zone between Cape Midia and Vama-Veche, Constanta Municipality Urban Plan, Mangalia Municipality Urban Plan, Eforie Nord and Eforie Sud Municipality Urban Plan. Integrated Coastal Zone Management (ICZM) was partially and inconsistently applied (Vaidianu et al, submitted). MSP is a complex process that involves interaction between values and interests of many different stakeholders, including institutions and regulations.

In this context, it was an urge for a comprehensive study of legal and institutional framework to illustrate the complexity and highlight the need for coordination between marine institutions and coastal or inland institutions. After EU accession, several actions were undertaken by central authorities. For example, Minister of Environment had the duty to elaborate a strategy for ICZM, which is still under development phase. In 2008, Minister of Regional Development initiated a project to define a methodology for framework content and elaboration of planning documentation for coastal zones - territorial planning of Black Sea coastal zone. From that time, the project crossed several stages and, since 2011, is under review at ministerial level, without any targets or deadlines. In the draft version, many issues have been addressed, among which the land-sea interactions.

In accordance with the EU Directive2014/89/EU, the Romanian Government is now implementing MSP. The process began two years ago, when MARSPLAN BS pilot project (financed by DG MARE-EASME) was just starting. In the early stage, the process was based on PlanCoast (2007), MISIS (2012-2014) and PEGASO (2010-2014) projects outputs. Maps and data from the mentioned past projects were used and established the basis for the MARSPLAN BS partnership. One year later, MSP directive was transposed into Romanian legislation under Governance Ordinance 18/2016, ratified by Law88/2017. As Romania has a centralized system, this law give full power to the Romanian Government to prepare the National Marine Plan. Within this framework, each Ministers involved have the duty and right to appoint one delegate and a substitute who bring in knowledge and expertise on drawing the plan. MSP Committee was settled in May 2017 by the Government Decision 406/2017 to elaborate the marine spatial plan and to monitor the marine spatial plan implementation. Twenty-five institutions are represented, led by the Prime Minister and the meetings are organized every 4 months. Within this regulation, no relation refers to the link with NCCZ, like in other countries (e.g. Germany), where the same institution/committee is in charge for both process in order to assure coherence and successful application. According to the new law on MSP, the plan will be designed before January 2020 (Article no. 23-1). The institutions mentioned above are responsible for drafting the plan based on maritime needs, conflicts, pressures and opportunities. Only after finalizing the elaboration process, the MSP Committee assures public consultation with stakeholders, competent public authorities and public in order to ensure decisional transparency in public administration (Article no 23-2).

\section{Methods}




\subsection{Quantitative approach: Spatial data}

An important prerequisite to implement MSP is understanding the spatial distribution of environmental, social and economic values, and of human activities. All data were very important from the early stage of this study since they represented all current uses and regulations, highlighting current overlaps and potential conflicts among users. Many users recognized that they were not able to spatialize their activities before seeing the maps. According to Smith and Brennan (2012), a map can produce reality as much as represent it and sometimes they do not accurately represent dynamic marine environments and complex interactions. For our study, we collected data (from projects and portals specialized in MSP data collection like European Atlas of Seas, EMODNET, CoCoNet, PlanCoast, OurCoast, BaltSpace, Adriplan, MISIS, PEGASO, TPEA on Atlantic Seas, etc.), produced, transformed, and classified the spatial data in order to create Geographical Information System (GIS) database for all variables relevant to decisions across the study area: Environmental data protected areas and NATURA 2000 sites, Geographic data, Transport data and ports, Oil and gas extractions, Oil and gas platforms, Fisheries and aquaculture, Cables and conducts, Tourism - bathing areas, Military activities, Other anthropogenic activities data. This database consists of a metadata catalogue and of datasets, in the form of shapefiles, having the same reference system (Fig. 2).

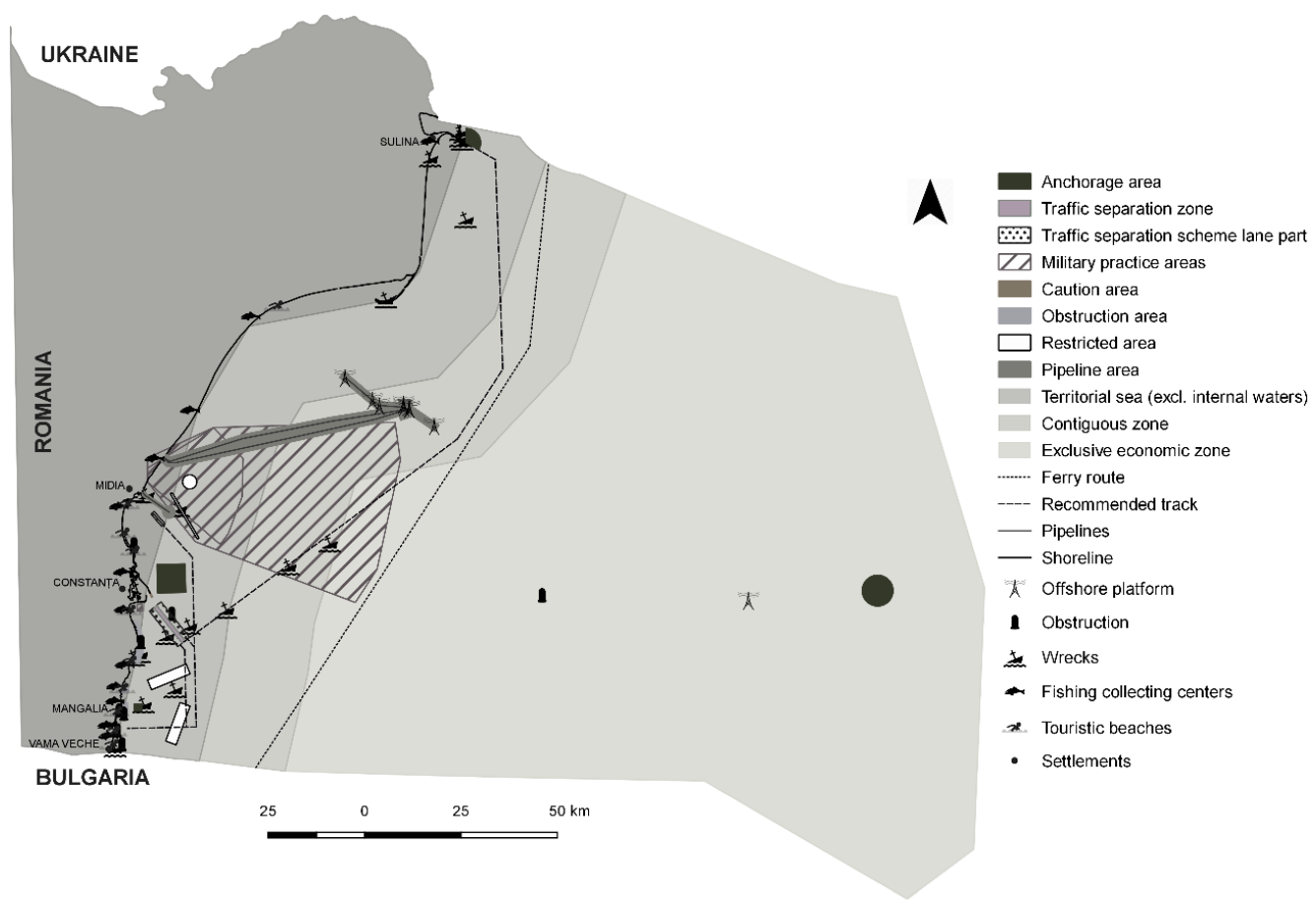

Fig. 2. Sea use of multi sectors in the study area (excepting protection sites). All current activities are represented as they are used by maritime and defence authorities

3.2. Qualitative approach: Workshops, questionnaires

Since 2015, several public participation actions such as workshops, focus-groups and meetings with stakeholders were performed with the aim of raise awareness and popularize this new process and requirement. From the beginning, a list of 'impacted stakeholders' was created to ensure that no important 
parties were omitted from the events. Invitations for participation to these wide-open actions were publicized and accessible to the public in a transparent manner via e-mail, project website and social media. Engagement with stakeholders from the first event was difficult because they were not familiar with this process, but next calls for participation have had a significant improvement due to the considerable efforts to deliver useful information and increase knowledge among targeted stakeholders. The majority of stakeholder groups and attendees at the workshops have mainly economic, ecologic, planning and research interests in decisions on the use of marine space.

In order to facilitate communication among participants and engage them from the early stage of plans design, the current spatial map, organized in different layers using GIS analysis of the existing uses, was presented. Table 1 presents a summary of the two main workshops undertaken in 2016 and 2017. Our study has showed how the work could be technically accomplished during the planning process without any intention to produce legally binding zoning plans. The general workshops outline was framed around the following main topics: Thinking (Setting the scene for MSP in Romania); Developing (Presenting maps with existing uses) and Framing (Developing a series of guidelines and policy recommendations regarding the MSP in Romania). During the workshops, several stakeholder sectors were identified, which typically belong to the private or operational sector, the governmental or public sector, or NGOs, and invited to participate in these events. For a more advanced analysis, stakeholder sectors were grouped under the following categories: shipping and ports, fisheries, tourism, national authorities, regional authorities, local authorities, science, NGOs and other marine-related activities.

Table 1

Number of participants

\begin{tabular}{lllllll}
\hline Managerial level & & Non-managerial level & & Total & Year & Location \\
\hline Workshop 1 & 9 & & 23 & 32 & 2016 & Constanta \\
National authorities & 2 & Shipping \& ports & 2 & & & \\
Regional authorities & 3 & Fisheries & 5 & & & \\
Local authorities & 4 & Tourism & 6 & & & \\
& & Science & 4 & & & \\
& NGOs & 5 & & & \\
Oorkshop 2 & 12 & & & & \\
National authorities & 2 & Shipping \& ports & 3 & & 2017 & Constanta \\
Regional authorities & 4 & Fisheries & 6 & & & \\
Local authorities & 6 & Tourism & 7 & & & \\
& & Science & 4 & & & \\
& NGOs & 5 & & & \\
Total & Other activities & 2 & \multirow{2}{*}{} & & \\
\hline
\end{tabular}

The applied methods have also used a semi-qualitative approach to obtain stakeholders' views, interests or potential conflicts in zoning process, together with comments or complaints that could delay the drafting of the marine plans. Seventy-one questionnaires were distributed to participants in order to collect a broader 
perception and attitudes of sea users and decision-makers. A broad range of organizations was included: National Agency for Fisheries and Aquaculture, Constanta Municipality, Danube Delta Federation of Fish Producers, Mare Nostrum NGO, ROMFISH National Association of Fishery Producers, National Institute for Marine Research and Development "Grigore Antipa“ Constanta, National Company Maritime Ports Administration S.A. Constanta, Junior Group, RO-PESCADOR Association, Ovidius University of Constanta, Institute of Nanotechnologies and Alternative Energy Sources, S.C. Eurolevel S.R.L., Green Urban NGO, Environmental Protection Agency Constanta, County Council Constanta - Urbanism and Territorial Planning, Civic Group Green Barricade, USONIA SRL, Dan Memet Design Office, Romanian Water Administration Dobrogea-Littoral, Maritime Hydrographic Directorate Constanta.

The questionnaire consisted in twenty-one questions designed following the ADRIPLAN project methodology and divided in five sections: General Information, Investments and development projects, Conflicts and obstacles, Synergies and European Policies (ADRIPLAN website). These methods allowed us to gain insights about their employment experiences and knowledge. For these reasons, qualitative data, based on the workshop and questionnaires approach, were used to discover stakeholders' experiences. Each workshop lasted about three hours. A power-point presentation explaining the study objectives was given at the beginning of first workshop and one presenting the current uses maps was given at the beginning of the second workshop. Data were collected using questions constructed to address the research objectives.

\section{Results}

The main approach was based on analysing the current situation of activities undertaken in the Romanian EEZ in order to have a proper image of stakeholders' perception regarding on what is now happening in the sea and identifying overlaps, potential synergies and gaps at legislative or institutional level. The next subsections will provide descriptions of the most important outputs during the project implementation process.

\subsection{Potential investments and development projects}

Need for investments and development projects has raised in Romania after EU accession in 2007. European funds were accessed through different funding programmes on environment, port infrastructure, fisheries or cultural purposes. Due to the bad environmental status in the Black Sea, many of projects focused on marine environment protection, marine litter, oil spills and control of ballast water. With the introduction of IMP and Blue Growth, actions related to hard coastal infrastructure have begun to be developed by authorities.

Feasibility studies were financed from European funds in order to establish the key areas of interventions, and in 2012 a Masterplan of about EUR 6 million was published. Based on its outputs, a total amount of EUR 220 million was spent within phase 2008-2015 for cliff consolidation works, rehabilitation and construction of dikes, emerged and submerged breakwaters and beach nourishment. Now, a second phase just started in 2017 with a budget of about EUR 500 million. At small-scale level, fishermen associations, maritime associations 
and NGOs have run projects on their activities. Within this context, three questions related to stakeholder development projects where addressed to the participants and the analysis revealed that more than $2 / 3$ have specific projects for next 5-10 years and, from these, 69\% have stated both direct and indirect utilisation of marine resources, while $25 \%$ highlighted a direct use and only $6 \%$ an indirect one. Regarding to the type of investments/activities or development programs, $18 \%$ mentioned environmental quality/target sector, $17 \%$ monitoring sector, followed by infrastructure and research with $12 \%$, respectively $11 \%$. The last positions are new production plants, human resources and other activities, each with $4 \%$ of answers (Fig. 3).

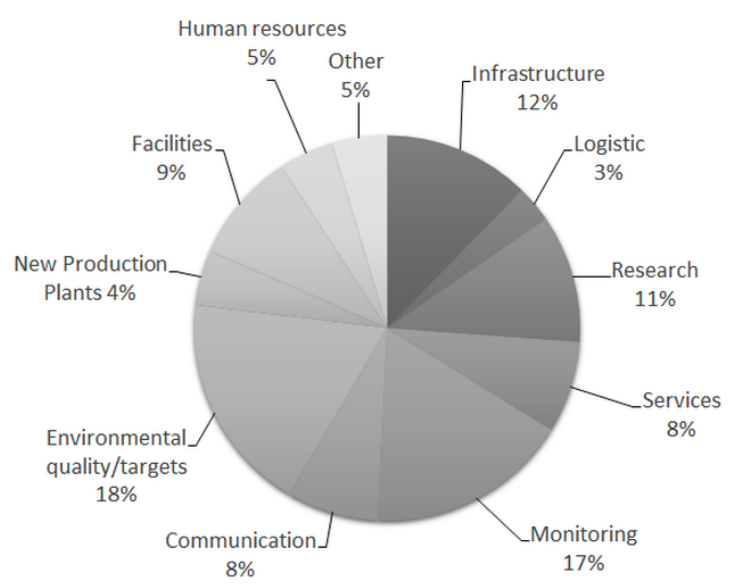

Fig. 3. Percentage of the total answers related to type of investments or development programs

\subsection{Concerns about barriers and conflicts}

Summarizing the stakeholders' opinions for the third section of the questionnaire, the results indicate a broad range of barriers when speaking about sea use. Fig. 4 illustrates the matrix represented on a Likert scale from 1 to 10 (lowest to highest importance). It is easily seen that the most iterated statement with the highest priority is the lack of clear legislation, followed by lack of a direct dialogue among stakeholders and bureaucratic barriers. On the second level, issues like lack of infrastructure, difficulties to access natural resources or interference with environmental protection law were mentioned. The lowest figures in answers were registered by lack of infrastructure and difficulties to access natural resources. There was a clear tendency for economic actors to be more concerned about lack of a direct dialogue among stakeholders, while the NGOs were more concerned about lack of a clear legislation. Concerns over interference with environmental protection law did not vary greatly according to the type of participant, with either nonsignificant relationships among activities. There were generally no big differences in concerns according to lack of infrastructure. 


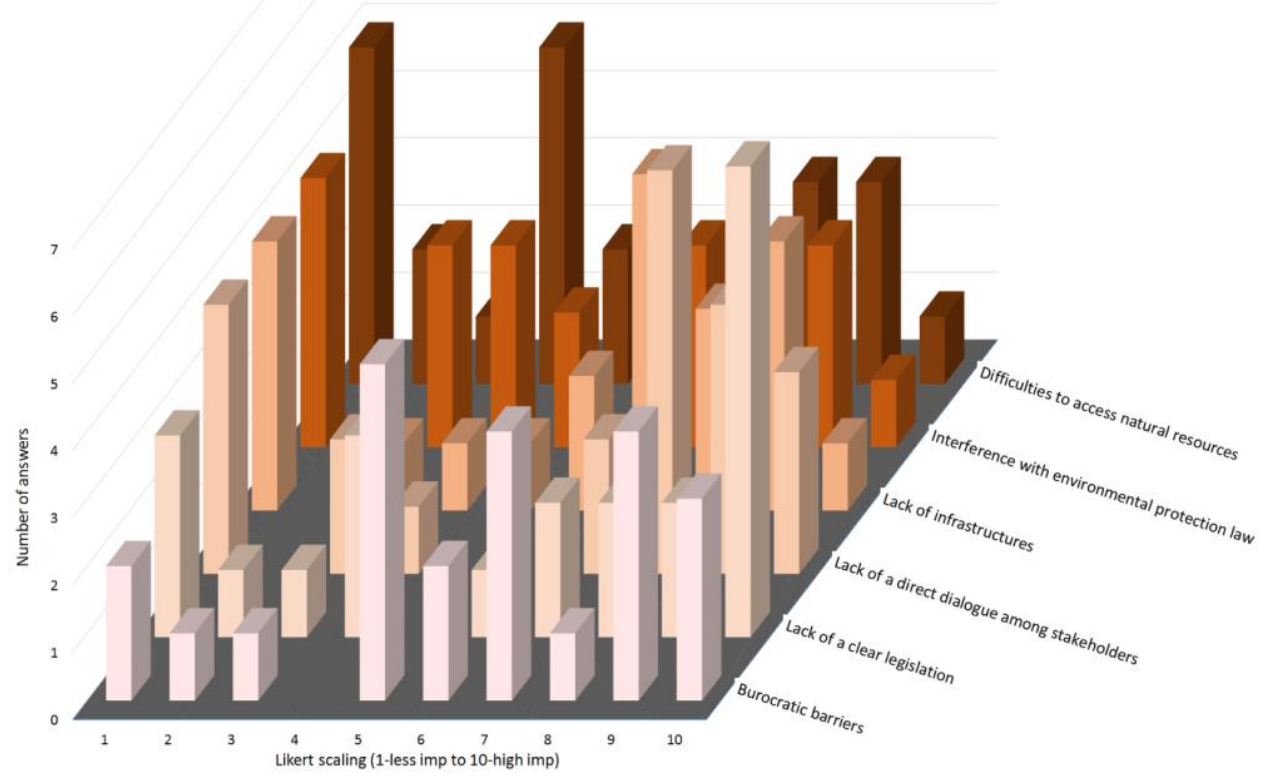

Fig. 4. 3-D graph illustrating the answers for barriers section, represented on a Likert scale ranging from 1 (lowest importance) to 10 (highest importance)

Fig. 5 displays public opinions about the conflicts in their activities development. The public identified negative effects of environmental pressures deriving from other marine activities as the most important conflict in their activity development. Despite significant importance at policy intervention, conflicts with other sectors for the utilisation of the same area marine resource were ranked as having the lowest impact. Conflicts that were perceived by the public to be relatively minor were predominantly related to specific conflicts with other marine or maritime sectors (economic). Conflicts with other sectors for the utilisation of the same marine area were seen to be moderate in the majority of stakeholders' opinions.

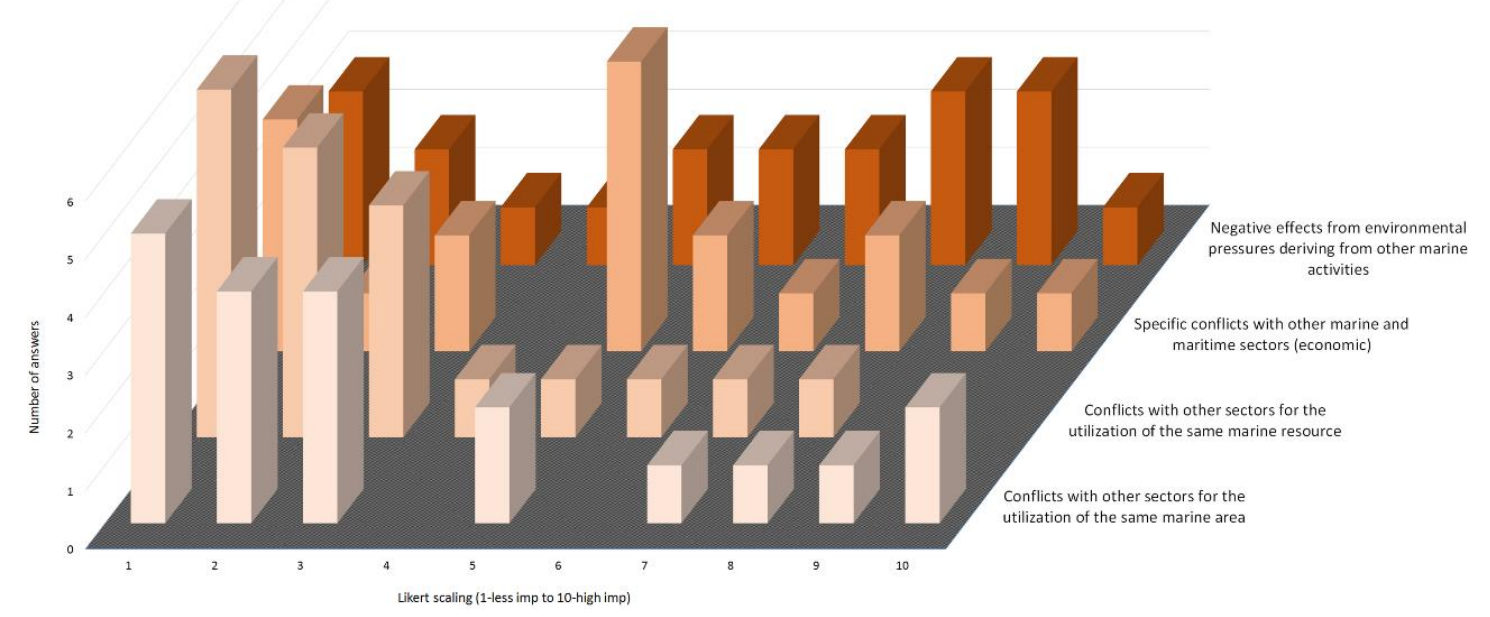

Fig. 5. 3-D graph illustrating the answers for conflicts question, represented on a Likert scale ranging from 1 (lowest importance) to 10 (highest importance) 


\subsection{Concerns about synergies}

The following graph illustrates how the public perceive the synergies with other marine sectors (Fig. 6). All participants responded that their activities could benefit from a tighter interaction with other marine sectors. When asked to mention what were the sectors with which they had a successful cooperation, the range was quite diverse. For example, the dominant synergy was related to environment and nature conservation and it was mentioned mostly by NGOs, academia and local authorities, while tourism and recreation were highlighted by fisheries sector, municipality and academia. In addition, military sector was considered most important for interactions by Romanian Waters Directorate, National Agency for Fishery and Aquaculture and the Design Office. No successful cooperation was registered with marine surveillance and only some with mineral extraction and dredging by fishermen associations. A small percentage has been recorded with marine research cooperation, despite the environmental issues to be addressed in the Black Sea.

12

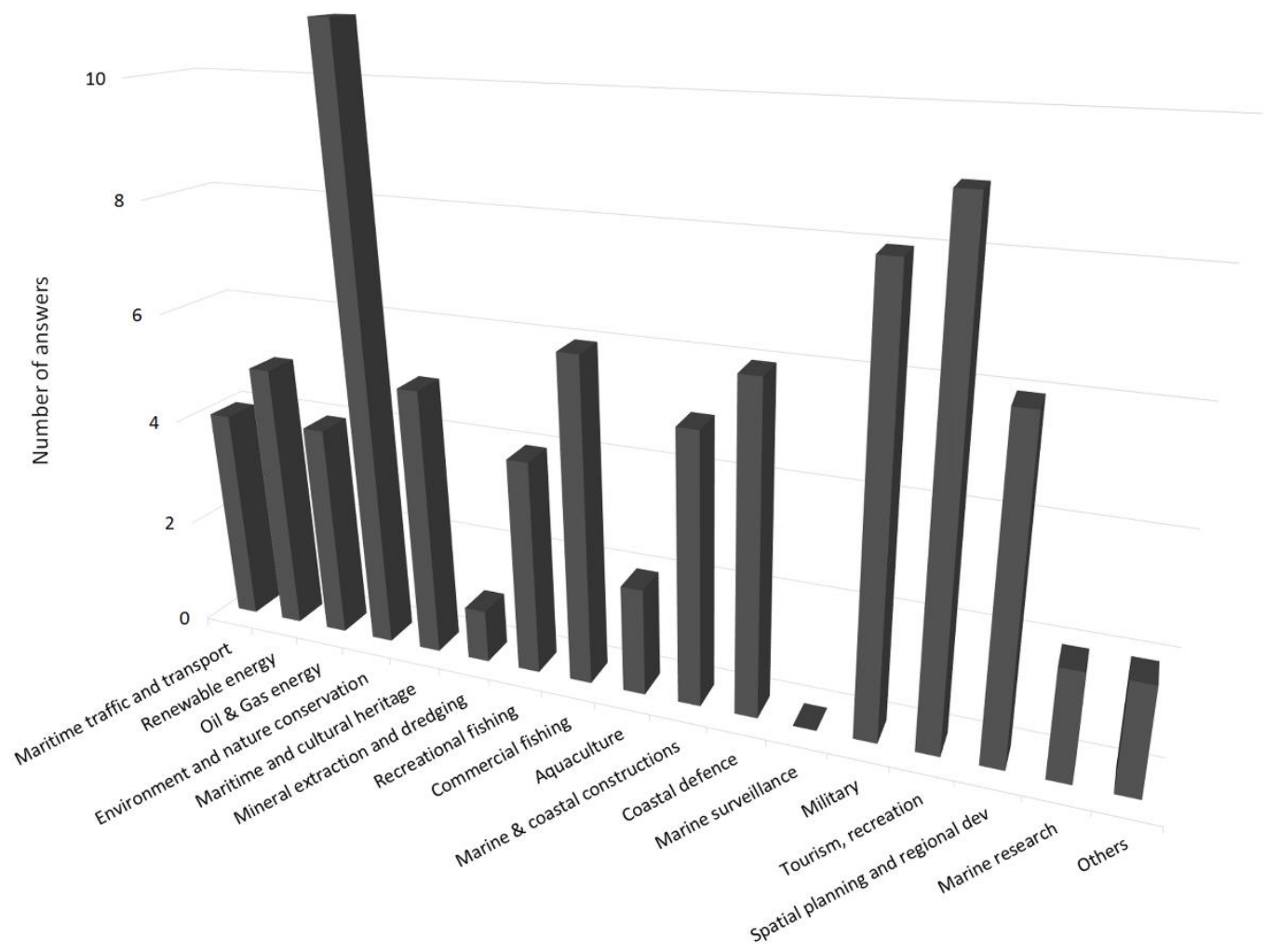

Fig. 6. The degree of successful interactions with other marine sectors

\subsection{Concerns about European policies}

Fig. 7 displays public opinions about the knowledge and acquaintance on MSP directive and ICZM. We looked in detail at this question in order to understand if stakeholders are aware of European legislation. 43\% did not hear about these policies, while $35 \%$ had some minor knowledge about them. Only $22 \%$ had a fully understanding of these processes. These results indicate a sensitive public awareness which could have a 
negative impact on MSP implementation. Moreover, during the workshops, they expressed a weak comprehension of Black Sea Synergy for a sustainable development of the whole basin. In the end, all participants agreed on the advantage of these regulatory instruments for their activities and considered clear legislation to be one of the most important issues in MSP implementation process.

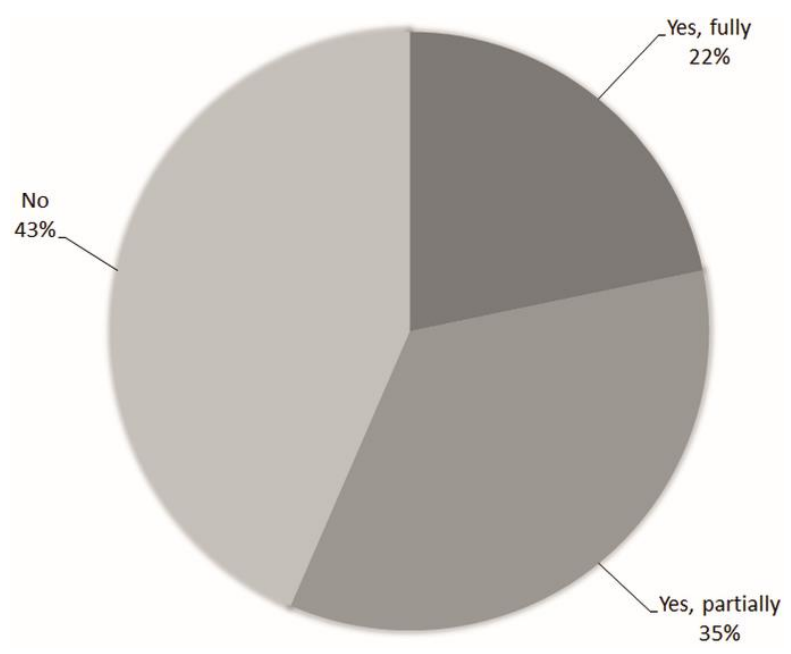

Fig. 7. The awareness degree on MSP and ICZM policies

\section{Discussion}

Several issues emerge as very important from this study. Participatory approach can identify conflicts among user groups because of policies misunderstanding, no management measures or weak governance. Even if the process begins simply, more attributes can be incrementally incorporated to perfect the process (Pomeroy and Douvere, 2008). On a practical note, the lower level of concern or knowledge about MSP can affect and create delays during the implementation process, but also for other cross-cutting initiatives like Black Sea Synergy or Blue Growth, as they aim to support marine economy through tourism, ocean energy, aquaculture, marine biotechnology and seabed mining. Maritime cooperation exists with other EU Member States (Bulgaria) and other Black Sea countries (bilateral cooperation) in the framework of EU initiatives in the areas of environmental monitoring, maritime surveillance and the new trans-boundary MSP implementation with Bulgaria.

But the main concern of Romanian stakeholders reflects the lack of clear legislation on marine environment. The two main regulatory processes (ICZM and MSP) are still in the early stages of implementation, despite the fact that the EU recommendation on ICZM dates back in 2002. The National Committee of Coastal Zone, the responsible body for endorsing all projects related to ICZM, has a weak power since its work is decided at national level, perceived as an additional source of instability in evolving governance at operational level (Gruber et al., 2010). In the MSP directive implementation, the central government has started with the methodology and drafting the plan one year ago, but only in the final stage it is planned to engage stakeholders and promote public participation. If these top-down approach issues are addressed and 
understood by the authorities, they may raise opportunities for societal and policy responses to improve engagement and acceptance of plans.

At this stage, it has a great importance to depict the expertise on maritime education and research for a better understanding of background issues. The level of education is generally good, with high levels of expertise in some maritime and coastal fields. However, there are gaps in fields like coastal management and business and administration which are poorly linked, leading to a limited contribution of research to innovation. Lack of human resources for coastal and marine management was identified as a key problem affecting local municipalities in charge for addressing coastal issues. No staff with a specific coastal management capacity is hired in municipalities, mainly because of low expertise as a result of the lack of educational programs at national level dealing with coastal and marine management training.

The fact that Romania has a sectorial orientation and not an area-based planning is mainly a result of the centralized power and geopolitical conditions in the Black Sea Basin. At national level, the statements exposed the lack of public dimension that is very central to the legitimacy and acceptance of MSP. The current approach can lead to inefficient marine plans or conflicts after approval at national level. Leaving out the stakeholders or involving them only in the final stage of plans drafting can raise problems and incomplete implementation in the future. There are successful processes in more advanced states in implementing MSP Directive, where stakeholder engagement is ensured in several occasions during the plan preparation: an initial 'joint workshop' to establish the plan's scope, content and objectives; pre-consultation on the draft; and consultation on the draft (Smith and Jentoft, 2017).

The research also revealed that many stakeholders still don't know what MSP process means, who has the mandate to create the plan and how are the preparatory steps progressing. One concern is that there are stakeholders with legitimate characters, but with little power in decision-making. Listening to the discussion during the meetings and reviewing participant questionnaires, it became clear that stakeholder opinions were very different and problems were identified about national control which was mainly focused on political situation. Moreover, when asked in a meeting on Integrated Maritime Policy in the Black Sea, conducted in February 2015, a former director in the Minister of Regional Development and Public Administration, Territorial Development Directorate emphasised:

MSP is not existing in RO. The governance mechanisms don't exist even with Bulgaria. First, the Romanian authorities must have a clear idea on MSP, parallel projects, common methodologies and a common framework. Also, the link between land and sea environments is lacking. In RO central authority makes the spatial planning. There is no open dialogue with local and regional authorities. The experts don't come to the public administration which indicates a gap between the administration, business and other stakeholders. (T.G.)

Hence, the implementation of MSP in Romania seems to be beyond the capacity of institutions because of the fragmented regulatory regime among different ministers. Minister of Foreign Affairs is currently the driving force behind Integrated Maritime Policy (IMP) development, with the Danube Strategy, Blue Growth and the Black Sea Synergy as its main policies; the EU IMP high-level focal point is the Minister of Transport; MSP is coordinated by Minister of Regional Development and Public Administration; ICZM process is coordinated 
by Minister of Environment; Fisheries sector is coordinated by Minister of Agriculture and Rural Development, through National Agency for Fisheries and Aquaculture. Regarding the attributions, the Government and County Councils play a complementary role at regional level for economic development (including maritime issues). Moreover, two important executive agencies belonging to the Ministry of Environment have the authority to manage at regional level: one for the Northern coast, named the Danube Delta Biosphere Reserve Authority (DDBRA), which was created to conserve and protect the natural heritage, but also for the wellbeing of the villagers in the area (Vaidianu, 2013a, Vaidianu, 2013b, Van Assche et al., 2013); and the second for the Southern coast, named Romanian Water Administration Dobrogea-Littoral, managing the coast, controlling the coastal domain and providing concession agreements for recreational facilities. Additionally, one explanation for the fast transposition of the EU directive on MSP as it is defined at EU level, without major changes and without addressing the specificities of national conditions, could be the relatively short delay registered for this step at minister level, just before the deadline, in late August 2016.

Furthermore, in 2016 a new structure called National Agency of Protected Areas was established for coordination of protected areas management including marine ones, but its efficiency is uncertain as this agency will have only a supervisory role, without regular funding. Beyond policy, there are many gaps in legislation, enforcement and safety. Sometimes conflicts between levels of government arise as a result of improper allocation of marine resources and unsuccessful cooperation with economic activities. Although there is now a framework for MSP, imposed by central institutions and national laws, some sectors like ports, fisheries and protected areas management have already followed international regulations and sectorial European policies which often are not fully understood at local level. For example, management plans for Natura 2000 site ROSPA Black Sea have not the role to impose an action plan for tourism development, but the custodian should be actively involved through a visiting strategy elaboration, which is not actually in place yet.

Moreover, attitudes and behaviours of participants seems to be influenced by many factors, such as economic, education or social factors and these should be taken into account when developing the policy at national level. For instance, the Black Sea marine environment is very different from geographic and ecologic lens imposed by the water regimes, semi-enclosed position or no current-induced water movements. In this respect, the MSP directive should be tailored considering all these specificities and characteristics.

In this study, GIS was used to produce maps for each marine sector for an easier visualisation of existing activities that facilitated communication with and between the stakeholders. The principal output of MSP is a zoning map for marine sectors and ecosystems, but authorities have to understand that MSP does not mean only a technical procedure. Here it comes the very important role of academia in raising awareness and increasing education among public. When the facilitator projected and presented them at the beginning of the workshops, many participants were excited to show how the activities are spatially spread and what were the overlaps occurred. Up to the end, lots of observations and suggestions come from public and even friendly 
trade-off discussions. The results of this study suggest that inviting marine users and regulatory institutions in the same room or table represents effective means of reducing conflict between zoning and facilitating MSP process.

\section{Conclusions}

The study identifies a big percentage of concerns related to MSP implementation at regulatory level, while the optimism appears when referring to the small amount of overlaps and conflicts. By resolving conflicts and regulating maritime activities, MSP can make a significant contribution to achieving Good Environmental Status in the Black Sea, taking into account the high level of pollution and promoting the importance of marine protected areas designation as a tool for sustainable seas and oceans. From policy review, the study revealed that there is a huge need for sharing of MSP-relevant information for a coherent planning in Romania. Understanding the policy background and response, relevant actors can contribute and act in a proper way, including other actors' insights. Appropriate spatial planning requires not only government support but also the cooperation of stakeholders to ensure sustainable development of marine economies. During the discussions with Romanian authorities, challenges of assessing the needs of interconnected ecosystems (including relevant EU and international legislation) were identified.

This survey has demonstrated that Romanian stakeholders have a relatively poor understanding of European, national and regional sea planning regulations. Based on this work, the authors endorse a call for key institutions and actors involved in MSP implementation to actively engage the impacted stakeholders and communities in the decisions that affect them by the instrumentality of following recommendations: a) identify stakeholders affected and ensure public participation through open meetings and workshops at each stage and at all levels, from local to national; b) Establish governance rules for authorities at central, regional and local levels; c) Draw plans and improve MSP by transparent regulations and frequent communication with stakeholders.

The future for MSP in Romania looks promising due to the high expertise of academia involved in the national committee, but resolutions taken by this committee could fail without political will. More EU initiatives and call for projects for Black Sea are required in order to fulfil the huge difference with other European regional seas like Baltic Sea or North Sea in projects number and funding level. Moreover, further steps and efforts are required to simulate and foresee marine systems dynamics and create scenarios through modelling, together with participatory actions. Finding the best ways to achieve these desiderates should be the target and challenge for authorities and planners in the near future.

\section{Acknowledgements}

This work was funded by a grant of the Romanian National Authority for Scientific Research and Innovation, CNCS-UEFISCDI, project number PN-II-RU-TE-2014-4-2479, Era.Net Rus-Plus BS STEMA 42/ 2016 and UB2008/2015. We are grateful to Stephen Jay for his fruitful explanations during the post-doctoral mobility stage and Adrian Stănică, Lucian Dumitrache and Florin Tatui for their useful discussions during the early 
stages of the analysis. The authors wish to express their gratitude to the interview and workshops participants who contributed so willingly to the research described in this article. We also thank the reviewers for their careful and insightful comments.

\section{REFERENCES}

Abramic, A., Martínez-Alzamora, N., González del Rio Rams, J., Ferrer Polo, J., 2015. Coastal waters environmental monitoring supported by river basin pluviometry and offshore wave data, Marine Pollution Bulletin, 92, 1-2, 80-89. https://doi.org/10.1016/j.marpolbul.2014.12.052

ADRIPLAN Website: http://adriplan.eu/ (Last accessed on 30.09.2016)

Ahler, C., Douvere, F., 2007. Visions for a Sea Change. Report of the First International Workshop on Marine Spatial Planning. Intergovernmental Oceanographic Commission and Man and the Biosphere Programme. IOC Manual and Guides, 46: ICAM Dossier, 3. Paris, France.

Appiott, J., Dhanju, A., Cicin-Sain, B., 2014. Encouraging renewable energy in the offshore environment, Ocean \& Coastal Management, 90, 58-64. https://doi.org/10.1016/j.ocecoaman.2013.11.001

Avoyan, E., van Tatenhove, J., Toonen, H., 2017. The performance of the Black Sea Commission as a collaborative governance regime, Marine Policy, 81, 285-292. https://doi.org/10.1016/j.marpol.2017.04.006

Becker-Weinberg, V., 2015. Portugal's legal regime on marine spatial planning and management of the national maritime space, Marine Policy, 61, 46-53. https://doi.org/10.1016/j.marpol.2015.06.014

Calado, H., Bentza, J., Ng, K., Zivian, A., Schaefer, N., Pringle, C., Johnson, D., Phillips, M., 2012. NGO involvement in marine spatial planning: A way forward? Marine Policy, 36, 382-388.

https://doi.org/10.1016/j.marpol.2011.07.009

DG MARE website. https://ec.europa.eu/maritimeaffairs/policy/maritime_spatial_planning_en, Last accessed on 23.11.2016.

DG MARE, 2014. Study to Support the Development of Sea Basin Cooperation in the Mediterranean, Adriatic and Ionian, and Black Sea, Task 4 Report: Black Sea - Identification of Elements for Sea Basin Cooperation, Contract Number MARE/2012/07 - Ref. No 2.

Edwards, R., Evans, A., 2017. The challenges of marine spatial planning in the Arctic: Results from the ACCESS programme, Ambio, 46 (Suppl 3), 486-496, https://doi.org/10.1007/s13280-017-0959-x

Ehler, C., 2014. A Guide to Evaluating Marine Spatial Plans, Paris, UNESCO. IOC Manuals and Guides, 70; ICAM Dossier 8. unesdoc.unesco.org/images/0022/002277/227779e.pdf (Last accessed on 27.07.2016.) 
Ehler, C., Douvere, F., 2007. Visions for a sea change. Report of the first international workshop on marine spatial planning. Intergovernmental oceanographic commission and man and the biosphere programme. In: IOC Manual and Guides 48, IOCAM Dossier 4. UNESCO, Paris.

Ehler, C., Douvere, F., 2009. Marine spatial planning: a step-by-step approach toward ecosystem-based management, intergovernmental oceanographic commission and man and the biosphere programme. In: IOC Manual and Guides, No 53, ICAM Dossier, No 6. UNESCO, Paris.

European Commission Communication, 2008. Roadmap for Maritime Spatial Planning: Achieving Common Principles in the EU.

European Commission, Blue Growth, 2012. Opportunities for Marine and Maritime Sustainable Growth, Brussels.

European MSP Platform website. http://www.msp-platform.eu/. Last accessed on 07.01.2017.

Flannery, W., Healy, N., Luna, M., Exclusion and non-participation in Marine Spatial Planning, Marine Policy, 88, 32-40, https://doi.org/10.1016/j.marpol.2017.11.001

Frau, A.R., 2010. Socioeconomic valuation of the marine environment in Wales: implications for coastal management, $\mathrm{PhD}$ thesis, School of Ocean Sciences, Bangor University, United Kingdom.

Gee, K., Kannen, A., Adlam, R., Brooks, C., Chapman, M., Cormier, R., Fischer, C., Fletcher, S., Gubbins, M., Shucksmith, R., Shellock, R., 2017. Identifying culturally significant areas for marine spatial planning, Ocean \& Coastal Management, 136, 139-147. https://doi.org/10.1016/j.ocecoaman.2016.11.026

Gissi, E., Suarez de Vivero, J.L., 2016. Exploring marine spatial planning education: Challenges in structuring transdisciplinarity, Marine Policy, 74, 43-57. https://doi.org/10.1016/j.marpol.2016.09.016

Gopnik, M., Fieseler, C., Cantral, L., McClellan, K., Pendleton, L., Crowder, L., 2012. Coming to the table: Early stakeholder engagement in marine spatial planning, Marine Policy, 36, 1139-1149. https://doi.org/10.1016/j.marpol.2012.02.012

Gruber, N., Kuhns, R., Steurer, J.F., Stănică, A., Lipan, I. C., Tofan, L., Mozingo, J., Roberge, J.C., Ehlinger, T., Ginther, P., Rosati, J.D. 2010. Development of a Coastal Systems Operations Center for the Institutional Strengthening of Coastal Management along the Romanian Black Sea, Watershed Management, 952-965.

Jay, S., Toonen, H.M., 2015. The power of the offshore (super-) grid in advancing marine regionalization, Ocean \& Coastal Management, 117, 32-42. https://doi.org/10.1016/j.ocecoaman.2015.08.002

Jones, J.S.P., Lieberknecht, L.M., Qiu, W., 2016. Marine spatial planning in reality: Introduction to case studies and discussion of findings, Marine Policy, 71, 256-264. https://doi.org/10.1016/j.marpol.2016.04.026 
Pınarbaşı, K., Galparsoro, I, Borja, A., Stelzenmüller, V., Ehler, C.N., Gimpel, A., 2017. Decision support tools in marine spatial planning: Present applications, gaps and future perspectives, Marine Policy, 83, 83-91. http://dx.doi.org/10.1016/j.marpol.2017.05.031

Pomeroy, R., Douvere, F., 2008. The engagement of stakeholders in the marine spatial planning process, Marine Policy, 32, 816-822. https://doi.org/10.1016/j.marpol.2008.03.017

Reed, M., 2008. Stakeholder Participation for Environmental Management: A Literature Review, Biological Conservation, 141, 2417-2431. https://doi.org/10.1016/j.biocon.2008.07.014

Ritchie, H., 2014. Understanding emerging discourses of Marine Spatial Planning in the UK, Land Use Policy, 38, 2014, 666-675. https://doi.org/10.1016/j.landusepol.2014.01.009

Rodrigues, N., 2017. A comparative analysis of holistic marine management regimes and ecosystem approach in marine spatial planning in developed countries, Ocean \& Coastal Management, 137, 185-197. https://doi.org/10.1016/j.ocecoaman.2016.12.023

Romanian Maritime Cluster, Available from: http://clustero.eu/romanian-maritime-cluster/, (Last accessed 28.12.2016)

Smith, G., Brennan, R.E., 2012. Losing our way with mapping: Thinking critically about marine spatial planning in Scotland, Ocean \& Coastal Management, 69, 210-216.

https://doi.org/10.1016/j.ocecoaman.2012.08.016

Smith, G., Jentoft, S., 2017. Marine spatial planning in Scotland. Levelling the playing field?, Marine Policy, 84, 33-41. http://dx.doi.org/10.1016/j.marpol.2017.06.024

Stanchev, H., Stancheva, M., Young, R., Palazov, A., 2017. Analysis of shoreline changes and cliff retreat to support Marine Spatial Planning in Shabla Municipality, Northeast Bulgaria, Ocean \& Coastal Management, in press. https://doi.org/10.1016/j.ocecoaman.2017.06.011

Tsilimigkas, G., Rempis, N., 2017. Maritime spatial planning and spatial planning: Synergy issues and incompatibilities. Evidence from Crete Island, Greece, Ocean \& Coastal Management, 139, 33-41. http://dx.doi.org/10.1016/j.ocecoaman.2017.02.001

Tuya, F., Haroun, R., Espino, F., 2014. Economic assessment of ecosystem services: Monetary value of seagrass meadows for coastal fisheries, Ocean \& Coastal Management, 96, 181-187.

https://doi.org/10.1016/j.ocecoaman.2014.04.032

United Nations Development Program, 2030 Agenda for Sustainable Development, http://www.undp.org/content/undp/en/home/sustainable-development-goals/goal-14-life-below-water/targets/, Last Accessed on 14.03.2017. 
Văidianu, N., 2013a. Fuzzy cognitive maps: diagnosis and scenarios for a better management process of visitors flows in Romanian Danube Delta Biosphere Reserve, Journal of Coastal Research, 65, 1063-1068. https://doi.org/10.2112/SI65-180.1

Văidianu, N., 2013b. Danube Delta Biosphere Reserve. Partnership between people and nature for sustainable development, Ars Docendi Publishing, Bucharest. (In Romanian)

Văidianu, N., Tătui, F., Ristea, M., Managing Coastal Resources and Uses through Multi-scale Governance Structures in Romania, Marine Policy. Submitted for publication.

Van Assche, K., Shtaltovna, A., Hornidge, A.K., 2013. Visible and Invisible Informalities and Institutional Transformation in the Transition Countries of Georgia, Romania, and Uzbekistan, in: N. Hayoz, C. Giordano (Eds.) Informality in Eastern Europe Structures, Political Cultures and Social Practices, Publisher: Peter Lang, 89-118. 